\title{
Which of the direct acting anti-viral agents is the better drug in terms of efficacy, cost and safety -Boceprevir or Telaprevir?
}

\begin{abstract}
$\operatorname{Mark}$ Aziz $^{1 *}$
\section{Abstract}

Objective: Hepatitis C virus can cause chronic hepatitis with $20-30 \%$ of those infected are developing liver cirrhosis and some developing hepatocellular carcinoma. It is a global health problem with 130-170 million people infected worldwide. Current treatment uses pegylated interferon and Ribavirin. As of 2011, two new drugs have been approved in the U.S.A and Europe, the protease inhibitors Boceprevir and Telaprevir. The aim of this structured review is to investigate which of these two new drugs is better in terms of efficacy, safety and cost. A literature search was conducted using various primary and secondary sources. A database search was conducted to find three journals for critical review.

Conclusion: The articles showed that the two drugs are equally effective and more effective than standard therapy. Boceprevir is potentially significantly cheaper. Boceprevir may also have a slightly better adverse effects profile. However, it is evident that direct clinical trials comparing the two drugs are required.
\end{abstract}

Keywords: HCV, Boceprevir, Telaprevir, Review

\section{Introduction}

History: In 1975, serological tests found a hepatitis virus, which was neither hepatitis A or B, named the non-A non$\mathrm{B}$ hepatitis virus $(1,2)$. It was estimated that the virus was caused by up to $10 \%$ of transfusions. It was also responsible for $75 \%$ of cases of transfusion associated hepatitis with only $25 \%$ caused by hepatitis B (3). The condition was associated with chronic infection of the liver and progression to liver cirrhosis.

The hepatitis $\mathrm{C}$ virus (HCV) was molecularly identified in 1988. In 1990, blood tests became available for the virus. This enabled screening of blood transfusion products and proved a link between $\mathrm{HCV}$ and the development of hepatocellular carcinoma $(1,2)$. Due to the amount of blood transfusions occurring in 1990, it was estimated that the ability to screen blood products for $\mathrm{HCV}$, prevented 40,000 infections at the time, or 111 infections per day (4).

Virology: HCV belongs to the hepacivirus genus, only member of that genus, and to the flavivirus family (5). 7 genotypes, named from 1 to 7 , and a number of subtypes (abcd...etc) have been identified. The genome consists of a single RNA positive strand, consisting of approximately 9600 bases. The genome contains of a single open reading frame, which codes for a 3000 amino acids polyprotein, that is then cleaved by proteases into at least 10 proteins.
One third of these proteins form the structural proteins of the virus, while 2 thirds are involved in the viral replication process. The structural proteins are the core protein and the envelope proteins E1 and E2 and the non-structural proteins are the NS2-NS5 proteins. In addition, there is a small p7 protein. The non-translated regions, which flank the open reading frame contain an internal ribosome entry site that is used to help in the translation of the viral RNA (6-9).

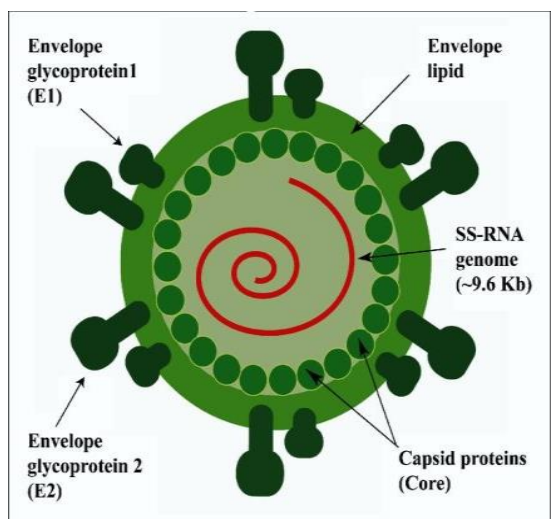

Figure 1: Structure of the HCV. Sharma SD. Hepatitis c. Molecular biology \& current therapeutic| options. Indian Journal of medical research (9) 
Replication: The virus enters host cells by binding to glycoaminoglycans and LDL receptors. Specialised cellular structures called the membranous webs, which are derived from the endoplasmic reticulum, are involved in forming a replication complex. Some of the non-structural proteins are involved in the formation of this replication complex.

The RNA is then used as a template for the virus replication and translation (6-10).

Epidemiology: The current global prevalence of $\mathrm{HCV}$ is around $2.35 \%$ of the world's population (11). Estimates vary but are in the range of 130-170 million people worldwide (12). The variation in these estimates stems from the fact that the majority of acute infections are asymptomatic; however, $80 \%$ of these patients will go on to develop chronic HCV infection (12). HCV has been implicated in $27 \%$ of cases of liver cirrhosis and $25 \%$ of cases of hepatocellular carcinoma (13). The prevalence rates vary from one region to another. The majority of the infected population lives in central/southeast Asia and in the western pacific region. The global epidemiology of the HCV can be seen in Figure 2. (12).

There are regional differences in prevalence rates, which can range from less than $1 \%$ of the population in northern European countries to 15\% of the population in Egypt (11). In Egypt, where the highest prevalence of HCV is found, the infection was spread by bad injection practice during mass public health campaigns to treat schistosomiasis in the 1960 s $(8,12)$. The common transmission routes of the HCV are percutaneous exposure to blood, cross-contamination during injections, sexual transmission and vertical transmission. The risk factors are listed in table 1 . Transmission through sexual intercourse, needle-stick injuries and vertical transmission are not as common (8, 13)..

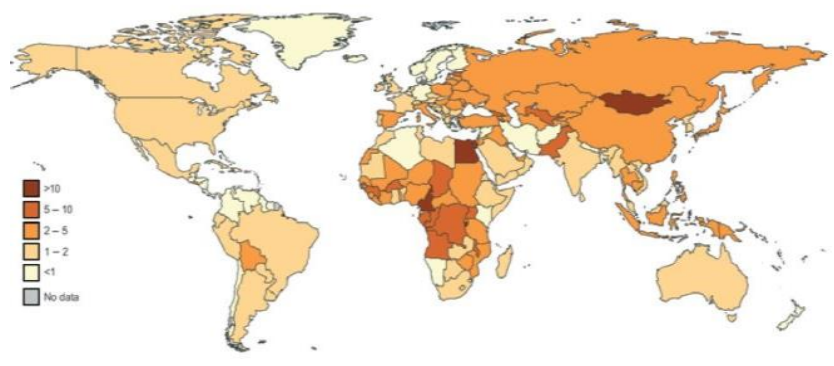

Figure 2: Global prevalence of HCV (12)

Clinical features: Exposure to $\mathrm{HCV}$ often causes an asymptomatic infection. In patients with acute hepatitis, there is usually an incubation period of approximately 2 to 12 weeks. Serum HCV RNA can usually be detected after exposure with 1-3 weeks. Unusual liver function tests can be detected after 8 weeks of exposure, with a raised alanine aminotransferase level.
Table 1: Risk factors for HCV infection $(12,13)$

Risk factors for $\mathrm{HCV}$ infection

\begin{tabular}{|l|}
\hline Blood transfusions \\
\hline Haemodialysis \\
\hline Haemophiliacs \\
\hline Transplantation patients \\
\hline Injection drug users \\
\hline Tattooing \\
\hline Sex with multiple partners \\
\hline Birth to an affected mother \\
\hline
\end{tabular}

The symptoms detected in acute hepatitis are usually nonspecific, mild and less than $25 \%$ of patients present with jaundice (see table 2) $(8,14,15)$. Patients who present with jaundice have lower rates of progression to chronic HCV infection (16). 20-40\% of patients with acute infection will spontaneously clear the virus. For the rest of the patients, the infection will progress to chronic infection. In the patients who spontaneously clear HCV, RNA is cleared within 3 months of onset; so if HCV RNA is detected after the onset with 6 months, then this is usually a sign of progress to a chronic infection (17).

From those patients who develop chronic hepatitis C, 20$30 \%$ will go on to develop liver cirrhosis. This usually takes 10-30 years to progress. There are several factors which can speed up this progression such as old age, male gender, race (e.g. African Americans) and excessive alcohol consumption $(15,18)$. Liver fibrosis occurs as a result of attempts to clear the virus by the body. An effective immune response will clear the virus, while an ineffective immune response will allow the virus to continue replication and recruit immune cells to the hepatocytes, which causes the hepatocellular damage (18). Liver biopsy is the gold standard for detection and staging of liver fibrosis and damage (16). If patients develop compensated liver cirrhosis, then the 5-year survival rate is $90 \%$, while the 5 year risk for progression to hepatocellular carcinoma is $7 \%$ and to decompensated liver cirrhosis is $18 \%$. Once patients progress to decompensated liver cirrhosis, the 5 year survival rate drops to $50 \%$ (19). Progress to cirrhosis and the deterioration of liver function to decompensated liver cirrhosis often occurs without symptoms, so it is usually recognised at latter stages (see table 2) (20). Approximately 1-2\% of patients will develop extra-hepatic manifestations (see table 2) (16).

Screening: The Scottish intercollegiate guidance network (SIGN) has recommended that certain high-risk groups should be screened for $\mathrm{HCV}$. The rationale is that treatment cannot be offered until diagnosis is confirmed and that these individuals are at higher risk of passing on their infection to others. The list of higher risk individuals for screening can be found in table 3 (21) 
Table 2: Signs and symptoms associated with Hepatitis C (8, 14-16)

\begin{tabular}{|l|l|l|}
\hline \multicolumn{2}{|l|}{ cirrhosis } & Membranoproliferative glomerulonephritis \\
\hline Jaundice & Ascites & Porphyria \\
\hline Fatigue & Oesophageal varices & Vitiligo \\
\hline Anorexia & Hepatorenal syndrome & Hodgkin's and Non-hodgkin's lymphoma \\
\hline Nausea & Hepatic encephalopathy & Autoimmune thyroiditis \\
\hline Dyspepsia & Dupuytren's ontracture & Seronegative arthritis \\
\hline Abdominal pain & Gynaecomastia & Sjogren's syndrome \\
\hline & Spider naevi & Cryoglobulinaemia, found in 50\% of patients causing: \\
\hline & Hepatosplenomegaly & - Arthralgia \\
& & - Purpura \\
& & - Fatigue \\
& & - Reynaud's phenomenon \\
& & - Renal disease \\
& & \\
\hline
\end{tabular}

Table 3: Screening targets as recommended by SIGN (21)

\section{The following groups should be tested for $\mathrm{HCV}$}

\begin{tabular}{l} 
Blood/tissue donors \\
\hline Patients on haemodialysis \\
\hline $\begin{array}{l}\text { Healthcare workers are involved in a career in a specialty } \\
\text { that exposes to high exposure risk procedures }\end{array}$
\end{tabular}

\section{The following groups should be offered an HCV test}

People with an unexplained constantly elevated alanine aminotransferase

People with a history of injecting drug use

Human immunodeficiency virus

(HIV) positive patients

Patients who received blood clotting factor concentrates before 1987

Patients who received blood and blood components before September 1991

Patients who received organ/tissue transplants in the UK before 1992

Children whose mother is infected with HCV

Healthcare workers who had percutaneous or mucous membrane exposure to blood which is, or is suspected to be, from a HCV infected source

People who have received medical or dental treatment in countries where

$\mathrm{HCV}$ is common

People with tattoos or piercings obtained in places with questionable infection control

People who had a sexual partner or contact with a patient with HCV.

The recommended screening tool by SIGN is facilitating the detection of antibodies to $\mathrm{HCV}$ using the ELISA method.
The tests have to be sensitive enough to detect a concentration of 50-100 IU/ml and are usually performed using reverse transcription polymerase chain reaction (21). A flowchart showing the diagnostic procedure is shown in figure 3 . 


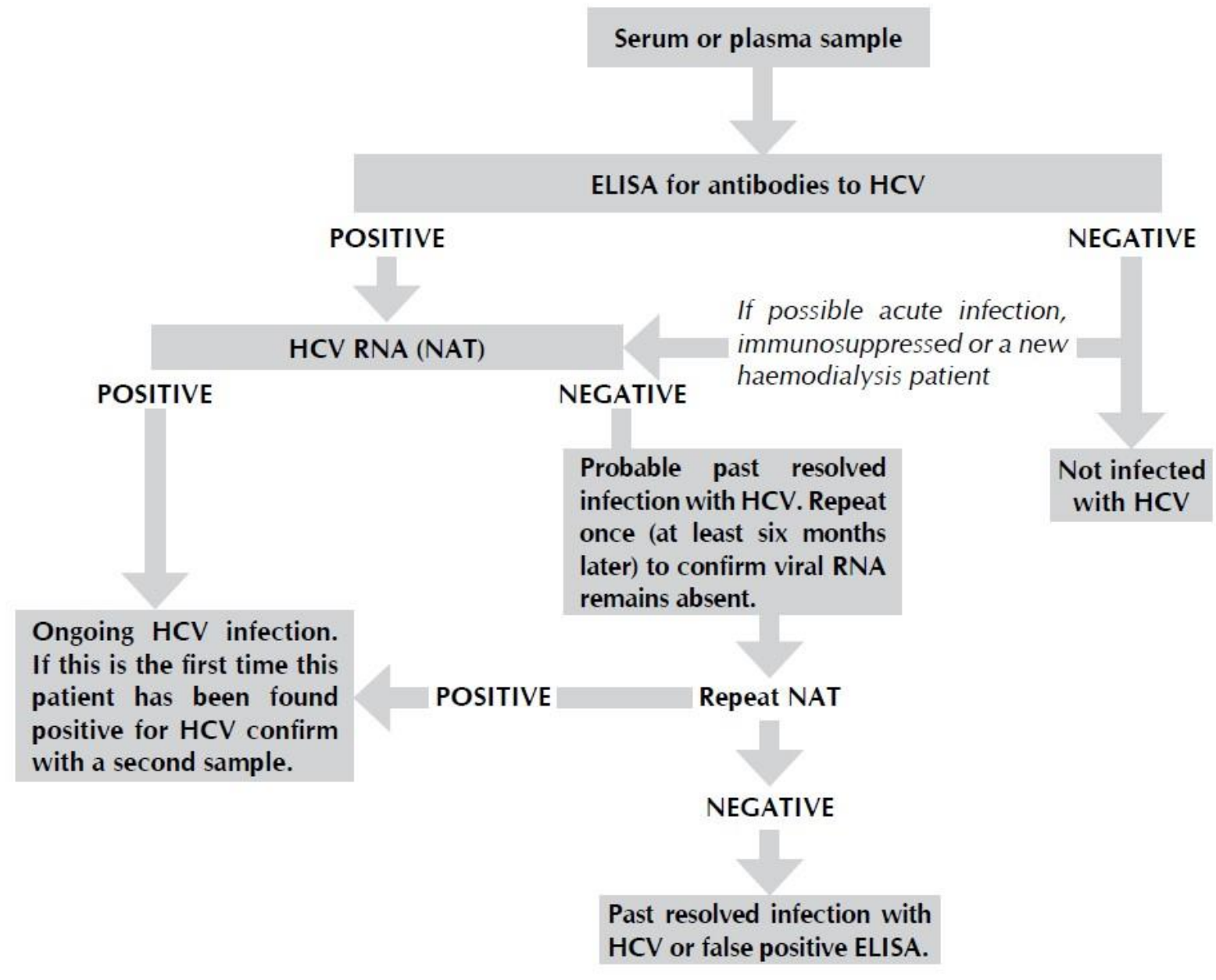

Figure 3: Diagnosis of hepatitis $C$ virus in non-infants. Taken from Management of Hepatitis C: a national clinical guideline: Scottish Intercollegiate Guidelines Network 2006, December 2006

Management: Treatment is for 3 to 6 months after infection if the virus is not cleared. Patients should be monitored and tested regularly for the 1 st 3 months. The recommended treatment is the use of Pegylated interferon (PEG-IFN) for 24 weeks .

For patients suffering from chronic infection, the recommended treatment is a combination of PEG-IFN and the nucleoside analogue Ribavirin (RBV). The treatment length depends on the genotype, based on HCV genotyping tests and can last from 12-48 weeks (21). There is currently no vaccine available for the prevention of $\mathrm{HCV}$ infection (22).

As of 2011, two direct acting anti-viral agents (DAA) have been approved in the U.S. and Europe. These are Boceprevir and telaprevir, which are protease inhibitors, that inhibit viral replication (23).
Further to the above, the aim of this study is to determinewhich of the direct acting anti-viral agents is the better drug in terms of efficacy, cost and safety Boceprevir or Telaprevir?

Method: A literature search was conducted using a variety of primary and secondary sources to conduct a general review of HCV. The sources used were textbooks, published guidelines and journals. Three databases were used: Medline, Scopus and web of knowledge. The key words used for the search and the inclusion and exclusion criteria are in table 4 below. In addition, the references of suitable articles were searched.

To select the articles for the structured review, a database search was conducted. Three databases were used: Medline, Scopus and web of knowledge. The broad terms Boceprevir and Telaprevir were used. Other inclusion and exclusion criteria are in table 5 below. The abstracts of the resulting articles were scanned to find suitable articles which address the question. 3 articles in total were chosen. 
Table 4: Keywords, inclusion and exclusion criteria for the literature research conducted.

\begin{tabular}{|lll|}
\hline Keywords & Inclusion criteria & Exclusion criteria \\
\hline Hepatitis C virus & Hepatitis C virus & Original research \\
\hline History & Review articles & Foreign language articles \\
\hline Discovery & English language & Paid articles \\
\hline Virology & Free articles & Veterinary articles \\
\hline Microbiology & 2002-2012 & \\
\hline Replication & Medicine articles & \\
\hline Epidemiology & Articles on immunology & \\
\hline Transmission & Articles on microbiology & \\
\hline Clinical features & & \\
\hline Monitoring HCV & & \\
\hline Management & & \\
\hline Testing & & \\
\hline Vaccines & & \\
\hline
\end{tabular}

Table 5: Keywords, inclusion and exclusion criteria for the literature research conducted to find articles for the structured review.

\begin{tabular}{|lll|}
\hline Keywords & Inclusion criteria & Exclusion criteria \\
\hline Boceprevir and Telaprevir & Review articles & Articles older than 2011 \\
\hline Cost & Original research articles & $\begin{array}{l}\text { Other types of articles not included in the } \\
\text { inclusion criteria }\end{array}$ \\
\hline Efficacy & Articles with the keywords & Foreign language articles \\
\hline Safety & Articles in journals & Non-free articles \\
\hline Clinical trials & Research conducted on humans & Other sources aside from journals \\
\hline & & Research conducted on non-humans \\
\hline
\end{tabular}

Table 6: Results of keyword searches in the various databases using the inclusion and exclusion criteria.

\begin{tabular}{|c|c|c|c|c|c|}
\hline & \multicolumn{5}{|c|}{ Keywords used } \\
\hline 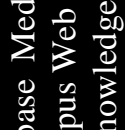 & $\begin{array}{l}\text { Boceprevir, } \\
\text { Telaprevir }\end{array}$ & $\begin{array}{l}\text { Boceprevir, } \\
\text { Telaprevir and } \\
\text { efficacy }\end{array}$ & $\begin{array}{l}\text { Boceprevir, } \\
\text { Telaprevir and } \\
\text { efficacy }\end{array}$ & $\begin{array}{l}\text { Boceprevir, } \\
\text { Telaprevir and } \\
\text { safety }\end{array}$ & $\begin{array}{l}\text { Boceprevir, Telaprevir and } \\
\text { clinical trials }\end{array}$ \\
\hline 용 & 73 & 5 & 11 & 7 & 28 \\
\hline$\tilde{\sigma}^{\tilde{\sigma}}$ & 115 & 21 & 89 & 61 & 115 \\
\hline & 67 & 8 & 28 & 14 & 31 \\
\hline
\end{tabular}

Table 7: Articles chosen for the structured review

\begin{tabular}{|c|c|c|c|}
\hline Article & Author & Title & Journal \\
\hline 1 & Shiffman ML, Esteban R. & $\begin{array}{l}\text { Triple therapy for HCV genotype } 1 \text { infection: } \\
\text { Telaprevir or boceprevir? }\end{array}$ & $\begin{array}{l}\text { Liver International. } \\
\text { 2012;32(SUPPL. 1):54-60. }\end{array}$ \\
\hline 2 & $\begin{array}{l}\text { Liu S, Cipriano LE, } \\
\text { Holodniy M, Owens } \\
\text { DK, GoldhaberFiebert JD. }\end{array}$ & $\begin{array}{l}\text { New protease inhibitors for the treatment of } \\
\text { chronic hepatitis C: A cost-effectiveness } \\
\text { analysis. }\end{array}$ & $\begin{array}{l}\text { Annals of Internal } \\
\text { Medicine. 2012;156(4):279 - } \\
90 .\end{array}$ \\
\hline 3 & $\begin{array}{l}\text { Cooper CL, Druyts } \\
\text { E, Thorlund K, } \\
\text { Nachega JB, El } \\
\text { Khoury AC, } \\
\text { O'Regan C, et al. }\end{array}$ & $\begin{array}{l}\text { Boceprevir and telaprevir for the treatment of } \\
\text { chronic hepatitis C genotype } 1 \text { infection: an } \\
\text { indirect comparison meta-analysis. }\end{array}$ & $\begin{array}{l}\text { Therapeutics and clinical risk } \\
\text { management. 2012;8:105-30. }\end{array}$ \\
\hline
\end{tabular}




\section{Discussion}

Shiffman and Esteban: Triple therapy for HCV genotype 1 infection: telaprevir or boceprevir? (24)

The first article reviewed is the review article by Shiffman and Esteban, looking at whether Telaprevir or Boceprevir should be used. The article mentions that both drugs are very effective, with similar outcomes. The article suggests that choosing between these 2 drugs should depend on several factors, to guide the decision process. These factors include, duration of therapy, adverse event profile and cost effectiveness (24).

Evaluation: Even though the author acknowledges the fact that there are no studies showing superiority of one drug over the other, it was still possible to achieve the study's aim, since the study looks at the best choice of the 2 drugs using several criteria, not just using drug efficacy. The study's relevance is still affected by this limitation. The clinical trials used to look at the efficacy of these drugs and at the adverse effect profiles, were well chosen, since these were the studies that led the food and drug administration to approve these drugs. However, the conclusions from these trials were related to the proposed duration of treatment of these new drugs. It would have been more useful to use studies, which look more directly at efficacy. Clearly this is a required area of research before the authors can evaluate the efficacy of the 2 drugs.

The conclusion that Telaprevir has a more streamlined treatment regimen is a very subjective rather than objective criterion. In addition, the simplicity of the regimen was not one of the factors stated in the initial aims set out by the authors. To investigate the relevance of this judgment, more objective evidence in the form of trials should be carried out to see if simplicity of regimen improves adherence and quality of life. Simpler regimens have been shown to do that in other conditions such as HIV, where sparing of protease inhibitors improved the adherence and quality of life (25).

The treatment duration for Boceprevir, is longer than the treatment duration of Telaprevir and can be close to 3 times as long as the treatment duration of Telaprevir. This is one of the factors mentioned in the aims of the study, to affect the choice of therapy. In this aspect, the authors are justified in preferring Telaprevir as the drug with the better treatment duration.

The authors commented about the cost of treatment, mentioning that the costs are similar for Telaprevir to the patients on Boceprevir, in patients on 32 and 44 weeks treatment, with only the patients on the 24 weeks treatment duration experiencing the reduced costs compared with Telaprevir. There are a few problems with this conclusion. The author does not mention whether the value of PEG-IFN $+\mathrm{RBV}$ treatment is taken into account since treatment with these agents could potentially last for longer in patients on Telaprevir, potentially incurring more costs. In addition, the difference in price between 32 weeks of Boceprevir and 12 weeks of Telaprevir

is approximately $\$ 14,000$ according to the costeffectiveness analysis conducted by Liu et al (2012) (26).
This accounts for over $28 \%$ reduction in the cost of treatment with Telaprevir, which is quite significant, so both costs should not be considered as similar.

It should also be taken into account the conflict of interest that the authors have declared, where they have declared ties with Merck and Vertex who produce Boceprevir and Telaprevir respectively $(24,26)$.

Liu et al: New Protease Inhibitors for the Treatment of Chronic Hepatitis C. A Cost-Effectiveness Analysis (26)

The 2nd article reviewed is an original research article by Liu et al, where a cost effectiveness analysis of Boceprevir and Telaprevir is performed. The article looks at the use of standard therapy, universal triple therapy and IL-28B guided triple therapy, where CC genotype patients will receive standard therapy and non-CC genotype patients will receive triple therapy. The study concludes that the triple therapy, whether universal or IL-28B guided, is cost effective (26).

Evaluation: The aims of this study were clear and the results were well presented in terms of money per quality adjusted life years (QALY). The use of QALYs should enable service providers to make appropriate decisions regarding these new drugs.

A huge drawback was that the study relied on research carried out by others, rather than own research on effectiveness and cost. As a result there were some downsides, such as the fact that the researchers considered a protease inhibitor similar to Boceprevir and Telaprevir rather than test these drugs themselves. In addition the researchers could not estimate adherence effectively and had to make assumptions about the adherence rate. The researchers also were not able to compare the use of triple therapy directly with the use of standard therapy in terms of effectiveness and cost.

The study to a great extent, considered the possible costs incurred in use of services and treatment. The study used previous research to consider patient's own spending, research in medical expenditure related to $\mathrm{HCV}$, data from medical claims data and other areas which could affect the overall cost of treatment, for example adherence. The authors have also importantly considered cost of treating fibrosis and of treating adverse events. In addition, the costs were adjusted to include inflation. However, the authors did not consider the wider social costs potentially saved. For example reducing amount of hours of work lost due to the illness and reduced transmission rates which can influence others in the society.

The study presented the results in a simple enough format to enable analysis of the cost-effectiveness of these drugs. The article also made recommendations regarding the use of these drugs as first or as second line treatment choices. However, the article did not present clearly the difference in QALYs achieved using the different treatment strategies.

The conclusions of this study are hard to justify since the figures achieved were described as reasonable, which is a subjective measure rather than an objective measure. These values should be compared with other treatments to explore 
their true cost-effectiveness. The authors mentioned the better value of Boceprevir, however a direct comparison with Telaprevir will be vital before healthcare providers commit to the use of either of these drugs. The study's conclusions about adherence and cost should still be useful to healthcare providers hoping to use one of these drugs.

The lack of evidence regarding the use of these drugs in real life decreases the usefulness of the results obtained from this research. This is due to the unpredictability of the use of these drugs. For example, the author mentioned that adherence tends to be higher in trials, so if the authors overestimated adherence then this would reduce the cost effectiveness of the drugs investigated.

Application of this study will also be difficult due to the fact that the patients used are monoinfected, treatment naive patients. Therefore, one cannot generalise these results with confidence to the general population.

One last problem with the application of this study is that the actual increases in QALYs, may not be significant enough to warrant extra treatment using the universal triple therapy, in the opinion of the different healthcare providers. Therefore the cost effectiveness will be heavily dependent on the judgement and the financial position of healthcare providers (26).

Cooper et al: Boceprevir and telaprevir for the treatment of chronic hepatitis $\mathrm{C}$ genotype 1 infection: an indirect comparison meta-analysis (27)

The third article reviewed is a meta-analysis conducted by Cooper et al. The meta-analysis looked at the efficacy and safety of both Boceprevir and Telaprevir in combination with PEG-IFN and RBV using an indirect comparison method. The articles used were phase 2 and 3 randomised placebo controlled trials. The author concluded that there are no significant differences between the 2 drugs clinically, however changes in the adverse effects profile could influence choice (27).

Evaluation: The article had clear aims, with clear population characteristics, measurable and suitable outcomes. SVR for example has been recommended by the SIGN guidelines as an accepted objective of treatment (21).

In general terms, the authors have included appropriate papers. The papers are all of random controlled trials, with a placebo for control, which is the highest level of evidence one can get in this scenario. There have been a few problems with trial selection, with the fact that the Telaprevir has only ever been compared with PEG-2a, while Boceprevir has only been compared with PEG-2b. This could be due to simply the availability of the trials, rather than poor study design of the meta-analysis. In addition it is a drawback of the study that none of the trials used compared Boceprevir and Telaprevir directly. However, the authors did carry out analysis to investigate the effects of carrying out indirect comparisons, which showed encouraging results.

The authors in this study seem to have carried out an extensive literature search. The authors looked at the references of published reviews, obtained help from the industry in finding relevant clinical trials, searched through non-English articles and included 2 publications, which are still in press. It is also good methodology to have 2 independent investigators carrying out the literature research and analysing the inter-observer agreement.

The trials used have shown some inter-differences in the results. For example the results for discontinuation of treatment in treatment naive patients on Boceprevir, showed a difference of 28 percentage points between the results of the 2 trials. This is possibly due to the differences in the numbers of participants used in the different trials, with some trials using over twice the number of participants as others. The authors have stated that they accounted for variation in populations and methodology by carrying out meta-regression and subgroup analysis.

In general the results of these studies should be applicable to the general population due to the fairly large cumulative number of participants involved. However, due to the problem of indirect comparisons rather than direct one, that study will never be quite as useful as a direct comparison between the 2 drugs. In terms of the adverse effects, which the authors say will be a key variable in choosing between one of the 2 agents, neutropenia was only shown to be significantly more likely in Boceprevir, in response guided therapy in treatment naive patients. With this being quite a specific finding, it is not very easy to apply this to the general population from this finding. However, for rash and pruritis, the study did find an increased risk for Telaprevir in most of the patient groups, so one can confidently derive this conclusion from the study.

It is worth mentioning, that despite the authors claiming no conflict of interest, 2 of the authors are linked to Merck, the producers of Boceprevir which is a possible undeclared conflict of interest (27).

\section{Conclusion}

In terms of efficacy, both drugs seem to be very effective but neither drug has been shown to be superior so far, as can be clearly seen from the study by Cooper et al.

In terms of cost, it seems that despite Shiffman and Esteban's claim that both costs are the same, according to the more accurate cost analysis carried out by Liu et al, Boceprevir probably has better value simply due to its lower price. However, both drugs are fairly cost-effective.

In terms of safety both drugs have a differing adverse effects profile. Still, as can be seen from the results of the meta-analysis by Cooper et al and looking at the study by Shiffman and Esteban, Boceprevir may have a lightly more tolerable adverse effects profile.

However, it is obvious from the critical analysis of these studies that further research comparing both of these agents is needed to fully answer the question of whether one of these drugs is superior to the other.

Conflict of Interest: The authors declare no potential conflicts of interest with respect to the research, authorship, and/or publication of this article. 
Author's Contributions: MA: Research the literature preparation of the article.

Ethical issues: All Authors declare, originality and ethical approval of research. Responsibilities of research, responsibilities against local ethics commission are under the Authors responsibilities.

\section{References}

1. Houghton M. Discovery of the hepatitis C virus. Liver international : official journal of the International Association for the Study of the Liver. [Historical Article Review]. 2009 Jan;29 Suppl 1:82-8.

2. Steven R. Recent advances in the molecular biology of hepatitis $\mathrm{C}$ virus. Journal of Molecular Biology. 2001;313(3):451-64.

3. Alter H. Discovery of non-A, non-B hepatitis and identification of its etiology. American Journal of Medicine. 1999;107(6 SUPPL. 2):1620.

4. Houghton $\mathrm{M}$. The long and winding road leading to the identification of the hepatitis C virus. Journal of hepatology. 2009;51(5):939-48.

5. Joyce MA, Tyrrell DLJ. The cell biology of hepatitis C virus. Microbes and Infection. 2010;12(4):263-71.

6. Tang H, Grisé H. Cellular and molecular biology of HCV infection and hepatitis. Clinical Science. 2009;117(2):49-65.

7. Von Hahn T, Steinmann E, Ciesek S, Pietschmann T. Know your enemy: Translating insights about the molecular biology of hepatitis C virus into novel therapeutic approaches. Expert Review of Gastroenterology and Hepatology. 2010;4(1):63-79.

8. Greenwood. D SR, Peutherer. J, Barer. M. Medical Microbiology a guide to microbial infections: pathogenesis, immunity, laboratory diagnosis and control. Edinburgh ; Churchill Livingstone/Elsevier 2007.

9. Sharma SD. Hepatitis c virus: Molecular biology \& current therapeutic options. Indian Journal of Medical Research. 2010;131(1):17-34.

10. Suzuki T, Aizaki H, Murakami K, Shoji I, Wakita T. Molecular biology of hepatitis $\mathrm{C}$ virus. Journal of Gastroenterology. 2007;42(6):411-23.

11. Negro F, Alberti A. The global health burden of hepatitis $\mathrm{C}$ virus infection. Liver international : official journal of the International Association for the Study of the Liver. [Editorial Introductory Research Support, Non-U.S. Gov't]. 2011 Jul;31 Suppl 2:1-3.

12. Lavanchy D. Evolving epidemiology of hepatitis C virus. Clinical microbiology and infection : the official publication of the European Society of Clinical Microbiology and Infectious Diseases. [Review]. $2011 \mathrm{Feb} ; 17(2): 107-15$.
13. Alter MJ. Epidemiology of hepatitis $\mathrm{C}$ virus infection. World journal of gastroenterology : WJG. [Review]. 2007 May 7;13(17):2436-41.

14. Santantonio T, Wiegand J, Tilman Gerlach J. Acute hepatitis C: Current status and remaining challenges. Journal of hepatology. 2008;49(4):625-33.

15. Modi AA, Liang TJ. Hepatitis C: A clinical review. Oral Diseases. 2008;14(1):10-4.

16. Chen SL, Morgan TR. The natural history of hepatitis C virus (HCV) infection. International Journal of Medical Sciences. 2006;3(2):4752.

17. Kamal SM. Acute hepatitis C: A systematic review. American Journal of Gastroenterology. 2008;103(5):1283-97.

18. Missiha SB, Ostrowski M, Heathcote EJ. Disease Progression in Chronic Hepatitis C: Modifiable and Nonmodifiable Factors. Gastroenterology. 2008;134(6):1699-714.

19. Bostan N, Mahmood T. An overview about hepatitis C: A devastating virus. Critical Reviews in Microbiology. 2010;36(2):91133.

20. Seeff LB. Natural history of chronic hepatitis C. Hepatology. 2002;36(5 I):S35-S46.

21. SIGN. Management of Hepatitis C: a national clinical guideline: Scottish Intercollegiate Guidelines Network2006 December 2006.

22. Ray R. Progress toward development of a hepatitis $\mathrm{C}$ vaccine with broad shoulders. Science Translational Medicine. 2011;3(94).

23. Butt AA, Kanwal F. Boceprevir and telaprevir in the management of hepatitis C virus-infected patients. Clinical Infectious Diseases. 2012;54(1):96-104

24. Shiffman ML, Esteban R. Triple therapy for HCV genotype 1 infection: Telaprevir or boceprevir? Liver International. 2012;32(SUPPL. 1):54-60.

25. Welsch C, Jesudian A, Zeuzem S, Jacobson I. New direct-acting antiviral agents for the treatment of hepatitis $\mathrm{C}$ virus infection and perspectives. Gut. 2012 May 1, 2012;61(Suppl 1):i36-i46.

26. Liu S, Cipriano LE, Holodniy M, Owens DK, Goldhaber-Fiebert JD. New protease inhibitors for the treatment of chronic hepatitis C: A cost-effectiveness analysis. Annals of Internal Medicine. 2012;156(4):279-90.

27. Cooper CL, Druyts E, Thorlund K, Nachega JB, El Khoury AC, O'Regan $\mathrm{C}$, et al. Boceprevir and telaprevir for the treatment of chronic hepatitis $\mathrm{C}$ genotype 1 infection: an indirect comparison meta-analysis. Therapeutics and clinical risk management. 2012 2012;8:105-30. 